\title{
Anti-cataract Effect of Resveratrol in High-Glucose-Treated Streptozotocin-Induced Diabetic Rats
}

\author{
Yoshihiro Higashi, Kentaro Higashi, Asami Mori, Kenji Sakamoto, Kunio Ishii, and \\ Tsutomu Nakahara* \\ Department of Molecular Pharmacology, Kitasato University School of Pharmaceutical Sciences; 5-9-1 Shirokane, \\ Minato-ku, Tokyo 108-8641, Japan. \\ Received May 1, 2018; accepted July 8, 2018
}

\begin{abstract}
Resveratrol, which is a polyphenol found in grapes, peanuts, and other plants, has health benefits for various chronic diseases. The aim of the present study was to examine the effect of resveratrol on cataract formation in diabetic rats. Male Wistar rats (7-week-old) were treated with streptozotocin, and the streptozotocin-treated animals were administered $5 \% \mathrm{D}$-glucose in drinking water to promote the formation of cataracts by inducing severe hyperglycemia. Resveratrol supplementation $(10$ or $30 \mathrm{mg} / \mathrm{kg} / \mathrm{d})$ in drinking water was initiated immediately after induction of diabetes was confirmed. The full lens images of the horizontal plane were captured with the digital camera system which we developed. Cataract formation was assessed by an observer-based scoring method and by quantitative analysis of digital images of the lens. Cataracts at the peripheral region of the lens were detected 2 weeks after induction of hyperglycemia and progressed depending on the length of the diabetic period. The majority of them developed severe cataracts after 9 weeks of hyperglycemia. Resveratrol did not prevent the appearance of diabetic cataracts but significantly delayed the progression of cataracts compared with controls. The contents of sorbitol and protein carbonyls in lenses of diabetic rats were higher than those of control rats. Resveratrol suppressed the increase in protein carbonyls, but not of sorbitol, in diabetic lenses. These results suggest that resveratrol delays the progression of diabetic cataracts partially through attenuation of oxidative damage to lens proteins. Resveratrol may be beneficial in preventing the progression of diabetic cataracts.
\end{abstract}

Key words cataract; diabetes; lens; oxidative stress; streptozotocin

Cataracts are among the most common complications of diabetes mellitus. The appearance and progression of cataracts depend on the severity of hyperglycemia and the duration of diabetes. ${ }^{1,2)}$ Surgery is widely accepted as the best method to treat cataracts. However, secondary deterioration in vision can sometimes occur after cataract surgery. ${ }^{3,4)}$ Therefore, it is important to establish non-surgical approaches for preventing the formation and progression of cataracts.

Several mechanisms that are suggested to be responsible for diabetic cataract formation include: enhanced oxidative stress, ${ }^{5-8)}$ activation of the polyol pathway, ${ }^{9-12)}$ and increased non-enzymatic glycation of lens proteins. ${ }^{13-15)}$ These mechanisms may be therapeutic targets for the treatment of diabetic cataracts.

Resveratrol (3,5,4'-trihydroxy-trans-stilbene) is a polyphenol found in grapes, peanuts, and other plants. ${ }^{16)}$ It exerts beneficial effects for cardiovascular diseases, ${ }^{17)}$ neurodegenerative diseases, ${ }^{18)}$ aging, ${ }^{19)}$ and cancer. ${ }^{20)}$ Reports also suggest that resveratrol has therapeutic potential against diabetic complications. ${ }^{21)}$ The underlying mechanisms for these effects are yet to be clearly elucidated; however, the anti-oxidative and anti-inflammatory effects of resveratrol may be involved. ${ }^{22)}$

Oxidative stress plays an important role in the onset and progression of diabetic cataracts. ${ }^{5-8)}$ Therefore, resveratrol may exert beneficial effects on this condition. In the present study, which uses a non-invasive and repeatable in vivo digital camera system to capture full lens images of small animals, ${ }^{23)}$ we assessed the effects of resveratrol on the formation of diabetic cataracts in rats. The levels of sorbitol and protein carbonyls are measures of polyol pathway activity and reactive oxygen-mediated protein oxidation, respectively. ${ }^{5,7,12}$ ) Therefore, we examined the effects of resveratrol on levels of sorbitol and protein carbonyls in the diabetic lens.

\section{MATERIALS AND METHODS}

Animals and Induction of Diabetes All experiments were performed in accordance with the Guidelines for Animal Experiments at Kitasato University as adopted by the university's Committee on the Care and Use of Laboratory Animals. These guidelines follow the tenets of the Association for Research in Vision and Ophthalmology statement regarding the Use of Animals in Ophthalmic and Vision Research.

Type 1 diabetes was induced in 7-week-old male Wistar rats using a procedure described previously. ${ }^{23)}$ In brief, 6-weekold male Wistar rats were obtained from the Charles River Breeding Laboratories (Tokyo, Japan). After $7 \mathrm{~d}$ of acclimation, diabetes was induced by a single intravenous injection of streptozotocin (65 mg/kg; Nacalai Tesque Inc., Kyoto, Japan) dissolved in citrate buffer $(\mathrm{pH}=4.5)$. Age-matched control rats were treated with an injection of an equal volume of the vehicle (citrate buffer). Induction of diabetes was confirmed by elevated non-fasting plasma glucose levels $(>350 \mathrm{mg} / \mathrm{dL}) 2 \mathrm{~d}$ after streptozotocin injection. Rats administered streptozotocin also received drinking water containing 5\% D-glucose to promote the formation of cataracts in a relatively short period of time. Plasma glucose levels were determined using a commercially available enzyme kit in accordance with manufacturer's instructions (Glucose Test Wako; Wako Pure Chemical Industries, Ltd., Osaka, Japan). 
A
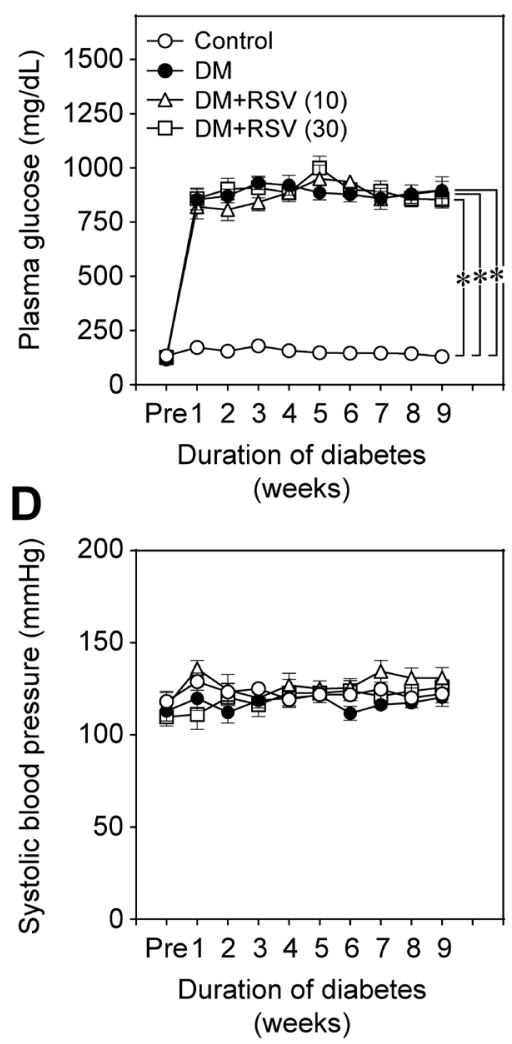

B

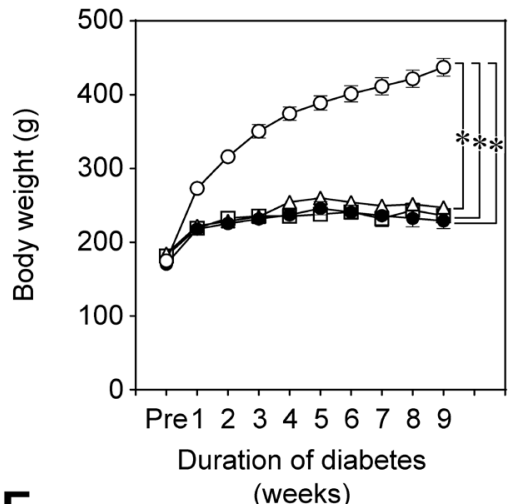

E

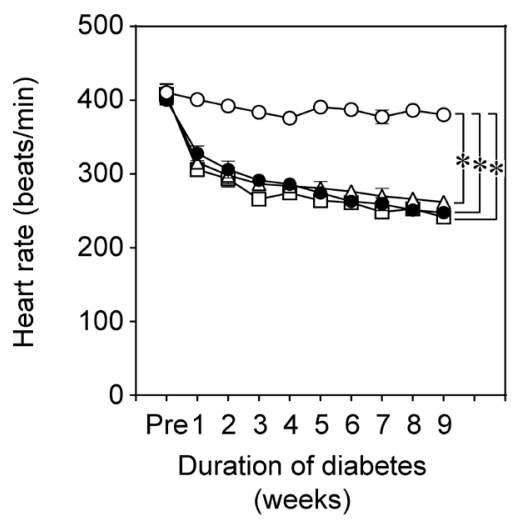

C

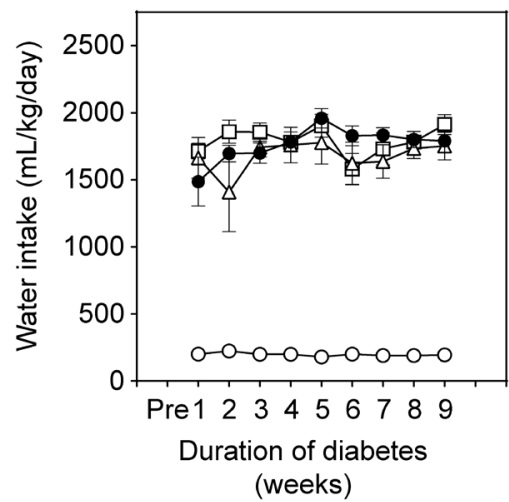

(weeks)

Fig. 1. Changes in Plasma Glucose (A), Body Weights (B), Water Intakes (C), Systolic Blood Pressure (D) and Heart Rate (E) in Control Rats (Control), Diabetic Rats (DM), Diabetic Rats Treated with $10 \mathrm{mg} / \mathrm{kg} / \mathrm{d}$ of Resveratrol [DM+RSV (10)] or 30 mg/kg/d of Resveratrol [DM+RSV (30)]

Each point with a vertical bar represents the mean \pm standard error (S.E.) from 6-10 animals. * $p<0.05$.

Treatment with Resveratrol Resveratrol was dissolved in ethanol and diluted in drinking water containing $5 \% \mathrm{D}$ glucose (final concentrations, 0.006 and $0.02 \mathrm{mg} / \mathrm{mL}$ ). Resveratrol treatment began immediately after diabetes induction was confirmed. Rats assigned to resveratrol treatment had access to the resveratrol drinking water solution ad libitum. The water intake of each rat was measured daily. Based on the water intake data, an estimated mean daily resveratrol dose was determined.

The animals were divided into 4 groups: control (Control; $n=9)$, diabetic rats (DM; $n=9)$, diabetic rats treated with $10 \mathrm{mg} / \mathrm{kg} / \mathrm{d}$ of resveratrol (DM+RSV $10 ; n=6)$, and diabetic rats treated with $30 \mathrm{mg} / \mathrm{kg} / \mathrm{d}$ of resveratrol (DM+RSV 30; $n=10$ ).

Evaluation of Cataracts The progression of cataracts was assessed on a weekly basis, as described previously ${ }^{23}$ (see Supplementary Materials and Methods).

Measurement of the Content of Resveratrol in the Lens Lenses were homogenized in $1 \%$ perchloric acid and then neutralized with $2 \mathrm{M}$ potassium carbonate. The homogenates were centrifuged $(5230 \times \boldsymbol{g}$ for $15 \mathrm{~min})$ at $25^{\circ} \mathrm{C}$. The concentration of resveratrol in the supernatants was measured by HPLC. Tissue resveratrol content was expressed as nanomoles per gram of wet tissue (nmol/g wet tissue).

Measurement of the Sorbitol Content in the Lens To measure the lens sorbitol content, rats in the Control, DM, and $\mathrm{DM}+\mathrm{RSV} 30$ groups were sacrificed at 1 week (Control, $n=3$; $\mathrm{DM}, n=4 ; \mathrm{DM}+\mathrm{RSV} 30, n=5$ ), and 9 weeks (Control, $n=3$; $\mathrm{DM}, n=3$; DM+RSV $30, n=4)$ after induction of diabetes.
The lens sorbitol content was measured as described previously. ${ }^{24,25)}$ In brief, tissues were homogenized in $16 \%$ perchloric acid and then neutralized with $2 \mathrm{M}$ potassium carbonate. The homogenates were centrifuged $(5500 \times \boldsymbol{g}$ for $10 \mathrm{~min})$ at $25^{\circ} \mathrm{C}$. The sorbitol content in the supernatants was measured using a commercially available kit according to the manufacturer's instructions (F-kit, D-sorbitol/xylitol; R-Biopharm AG, Darmstadt, Germany). The lens sorbitol content was expressed as micromoles per gram of wet tissue ( $\mu \mathrm{mol} / \mathrm{g}$ wet tissue).

Measurement of the Protein Carbonyl Content in the Lens Lenses were homogenized in $1-2 \mathrm{~mL}$ of cold phosphate buffer per $1 \mathrm{~mm}$ ethylenediaminetetraacetic acid (EDTA) $(\mathrm{pH}=6.7)$. The homogenates were centrifuged $(8700 \times \boldsymbol{g}$ for $15 \mathrm{~min})$ at $4^{\circ} \mathrm{C}$. The protein carbonyl content was measured using a commercially available kit according to the manufacturer's instructions (Protein carbonyl Assay Kit, Cayman Chemical, Ann Arbor, MI, U.S.A.). The protein carbonyl content in the lens was expressed as nanomoles per milligram of protein (nmol/mg protein).

Measurements of Systolic Blood Pressure and Heart Rate Rat systolic blood pressure and heart rate were measured under conscious conditions once per week with a tailcuff sphygmomanometer (BP-98 A, Softron, Tokyo, Japan).

Data Analyses All values are presented as means \pm standard error (S.E.). Tukey's test were used for the comparisons among more than 2 groups, respectively (GraphPad, San Diego, CA, U.S.A.). For comparing the time course changes in the experimental group, we performed the Bonferroni-Dunn test for multiple comparisons after a two- 


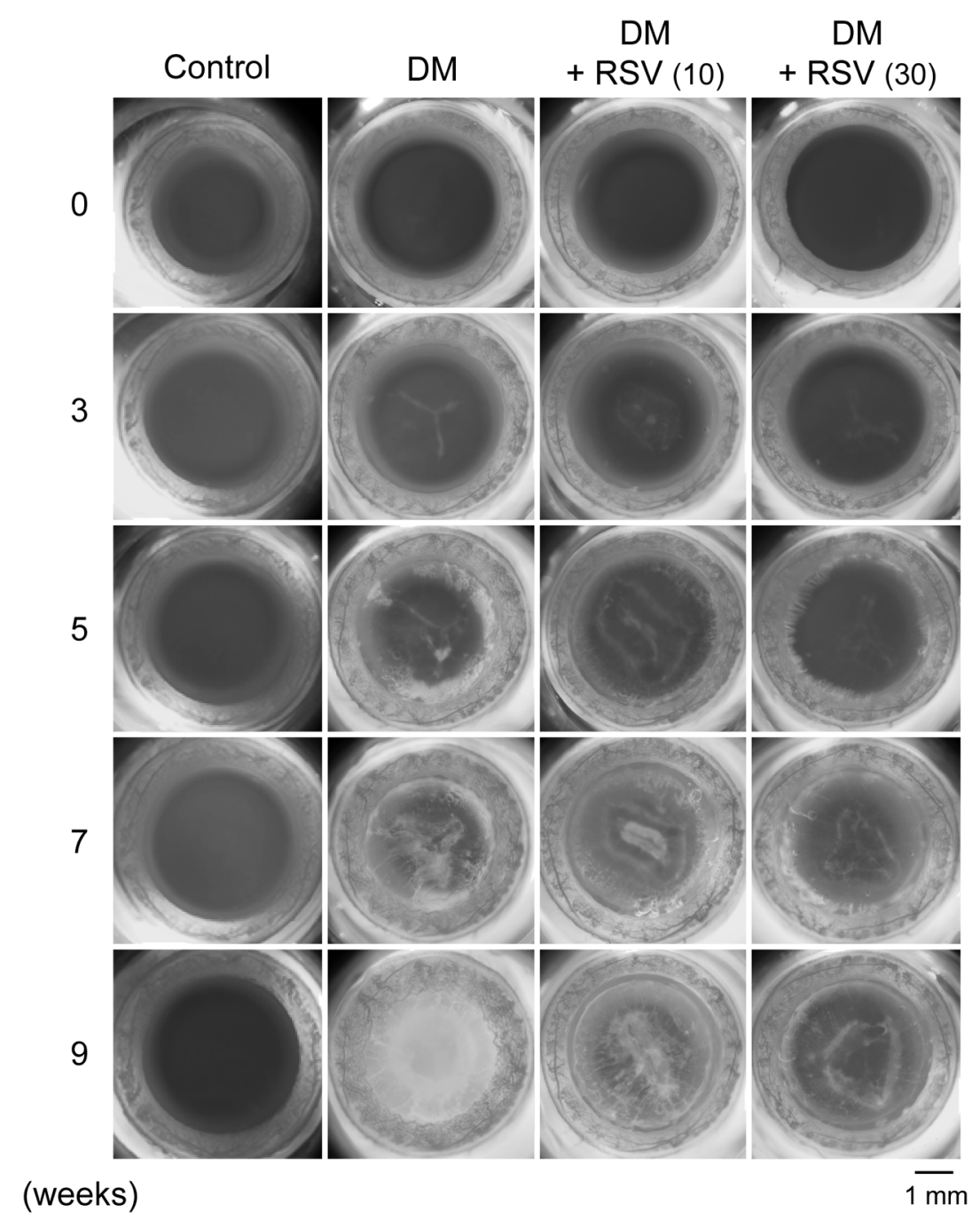

Fig. 2. Representative Lens Images in the Horizontal Plane in a Control Rat (Control), a Diabetic Rat (DM), a Diabetic Rat Treated with $10 \mathrm{mg} / \mathrm{kg} / \mathrm{d}$ of Resveratrol [DM+RSV (10)] or $30 \mathrm{mg} / \mathrm{kg} / \mathrm{d}$ of Resveratrol [DM+RSV (30)]

The lens of the control rat was clear during the study. In the lens of the diabetic rat, the cataract progressed in a time-dependent manner. In contrast, the progression of cataracts was delayed in diabetic rats treated with resveratrol.

way repeated-measures ANOVA.

\section{RESULTS}

Plasma Glucose Levels, Body Weights, Water Intakes, Blood Pressure and Heart Rate Non-fasting plasma glucose levels were significantly higher in the DM group than in the Control group (Fig. 1A), whereas body weights were significantly lower in the DM group than in the Control group (Fig. 1B). There were no significant differences in plasma glucose levels and body weights among the DM, DM+RSV 10, or $\mathrm{DM}+\mathrm{RSV} 30$ groups. The average water intakes in the Control, DM, DM+RSV 10, and DM+RSV 30 groups were 195 \pm 8 $(n=8), 1736 \pm 42(n=9), 1677 \pm 18(n=6)$, and 1790 $\pm 25(n=10)$ $\mathrm{mL} / \mathrm{kg} / \mathrm{d}$, respectively. Water intake was significantly $(p<0.05)$ higher in diabetic rats than in Control rats. Resveratrol treatment did not affect water intake (Fig. 1C). Based on the water intake data, the daily intake of resveratrol in the DM+RSV 10 and $\mathrm{DM}+\mathrm{RSV} 30$ groups was estimated to be $11.2 \pm 0.4$ and $35.8 \pm 0.3 \mathrm{mg} / \mathrm{kg} / \mathrm{d}$, respectively. Resveratrol had no apparent effect on systolic blood pressure (Fig. 1D). Rats with induced diabetes had lower heart rates than control rats, but the re-
Table 1. Resveratrol Content of Resveratrol (nmol/g Wet Weight) in the Lens after 9 Weeks of Hyperglycemia

\begin{tabular}{ccc}
\hline \hline $\begin{array}{c}\mathrm{DM} \\
(n=4)\end{array}$ & $\begin{array}{c}\mathrm{DM}+\mathrm{RSV}(10) \\
(n=3)\end{array}$ & $\begin{array}{c}\mathrm{DM}+\mathrm{RSV}(30) \\
(n=6)\end{array}$ \\
\hline n.d. & $1.9 \pm 0.5$ & $7.6 \pm 1.9$ \\
\hline
\end{tabular}

Values are expressed as mean \pm S.E. n.d. indicates not detectable.

duced heart rate was not affected by resveratrol (Fig. 1E).

Resveratrol Content in the Lens Table 1 summarizes resveratrol levels in the lenses at the end of the ninth week in the DM, DM+RSV 10, and DM+RSV 30 groups. Resveratrol contents reflected a dose-dependent pattern.

Cataract Formation Figure 2 shows the representative lens images of the horizontal plane in rats of the Control, DM, $\mathrm{DM}+\mathrm{RSV}$ 10, and DM+RSV 30 groups, and Table 2 summarizes the cataract scores in each experimental group.

All lenses in the Control group were clear throughout the experimental period. In the DM group, cataracts were observed in $77 \%$ of lenses (23/30) 2 weeks after diabetes induction. In contrast, in the DM+RSV 10 and DM+RSV 30 
groups, the appearance of cataracts was detected in $75 \%$ of lenses $(9 / 12)$ and in $60 \%$ of lenses (12/20), respectively. The cataracts progressed with time over the length of the diabetic period, and $40 \%$ of lenses (12/30) developed hypermature cataracts 9 weeks after induction of diabetes. Hypermature cataracts in the DM+RSV 10 and DM+RSV 30 groups occurred in $17 \%$ of lenses $(2 / 12)$ and $5 \%$ of lenses $(1 / 20)$, respectively.

A

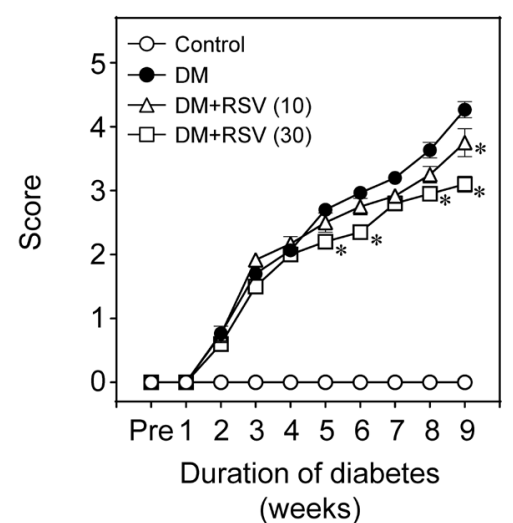

The results obtained from quantitative analyses are summarized in Fig. 3. Similar results were obtained with the scoring method (Fig. 3A) and the measurement of the opaque area in the central region (Fig. 3B). These results clearly show that the progression of cataracts until 3 weeks after induction of diabetes was practically identical between the DM and DM+RSV groups. However, at 5 weeks after induction or later, a dose-

B

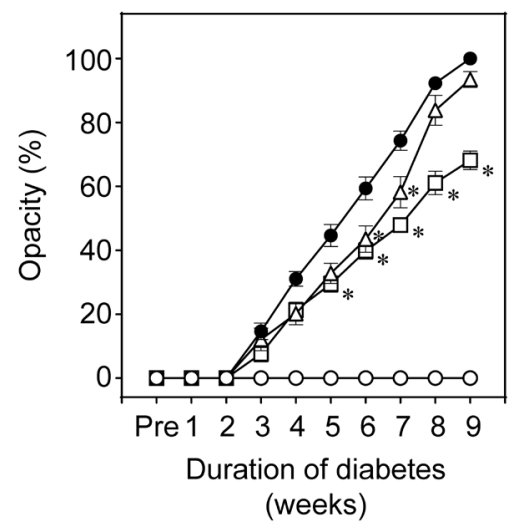

Fig. 3. Changes in the Cataract Score and Opacity in the Central Region of the Lens in Control Rats (Control), Diabetic Rats (DM), Diabetic Rats Treated with $10 \mathrm{mg} / \mathrm{kg} / \mathrm{d}$ of Resveratrol [DM+RSV (10)] or $30 \mathrm{mg} / \mathrm{kg} / \mathrm{d}$ of Resveratrol [DM+RSV (30)]

Each point with a vertical bar represents the mean \pm S.E. from $6-10$ animals. ${ }^{*} p<0.05$, compared with the DM group.

Table 2. Effect of Resveratrol on the Cataract Formation in Streptozotocin-Treated Rats Given 5\% D-Glucose in Their Drinking Water

\begin{tabular}{|c|c|c|c|c|c|c|c|c|c|c|c|c|}
\hline \multirow{2}{*}{$\begin{array}{c}\text { Week(s) } \\
\text { Score }\end{array}$} & \multicolumn{4}{|c|}{1} & \multicolumn{4}{|c|}{2} & \multicolumn{4}{|c|}{3} \\
\hline & Control & $\mathrm{DM}$ & $\begin{array}{c}\mathrm{DM}+\mathrm{RSV} \\
(10)\end{array}$ & $\begin{array}{c}\mathrm{DM}+\mathrm{RSV} \\
(30)\end{array}$ & Control & DM & $\begin{array}{c}\mathrm{DM}+\mathrm{RSV} \\
(10)\end{array}$ & $\begin{array}{c}\mathrm{DM}+\mathrm{RSV} \\
(30)\end{array}$ & Control & $\mathrm{DM}$ & $\begin{array}{c}\mathrm{DM}+\mathrm{RSV} \\
(10)\end{array}$ & $\begin{array}{c}\mathrm{DM}+\mathrm{RSV} \\
(30)\end{array}$ \\
\hline 0 & 20 & 30 & 12 & 20 & 20 & 7 & 3 & 8 & 20 & 0 & 0 & 0 \\
\hline 1 & 0 & 0 & 0 & 0 & 0 & 23 & 9 & 12 & 0 & 9 & 1 & 10 \\
\hline 2 & 0 & 0 & 0 & 0 & 0 & 0 & 0 & 0 & 0 & 21 & 11 & 10 \\
\hline 3 & 0 & 0 & 0 & 0 & 0 & 0 & 0 & 0 & 0 & 0 & 0 & 0 \\
\hline 4 & 0 & 0 & 0 & 0 & 0 & 0 & 0 & 0 & 0 & 0 & 0 & 0 \\
\hline 5 & 0 & 0 & 0 & 0 & 0 & 0 & 0 & 0 & 0 & 0 & 0 & 0 \\
\hline Week(s) & \multicolumn{4}{|c|}{4} & \multicolumn{4}{|c|}{5} & \multicolumn{4}{|c|}{6} \\
\hline Score & Control & $\mathrm{DM}$ & $\begin{array}{c}\mathrm{DM}+\mathrm{RSV} \\
\quad(10)\end{array}$ & $\begin{array}{c}\mathrm{DM}+\mathrm{RSV} \\
(30)\end{array}$ & Control & $\mathrm{DM}$ & $\begin{array}{c}\mathrm{DM}+\mathrm{RSV} \\
(10)\end{array}$ & $\begin{array}{c}\mathrm{DM}+\mathrm{RSV} \\
(30)\end{array}$ & Control & $\mathrm{DM}$ & $\begin{array}{c}\mathrm{DM}+\mathrm{RSV} \\
(10)\end{array}$ & $\begin{array}{c}\mathrm{DM}+\mathrm{RSV} \\
\quad(30)\end{array}$ \\
\hline 0 & 20 & 0 & 0 & 0 & 20 & 0 & 0 & 0 & 20 & 0 & 0 & 0 \\
\hline 1 & 0 & 2 & 0 & 0 & 0 & 0 & 0 & 0 & 0 & 0 & 0 & 0 \\
\hline 2 & 0 & 24 & 10 & 20 & 0 & 7 & 6 & 15 & 0 & 1 & 3 & 11 \\
\hline 3 & 0 & 4 & 2 & 0 & 0 & 23 & 6 & 5 & 0 & 28 & 9 & 9 \\
\hline 4 & 0 & 0 & 0 & 0 & 0 & 0 & 0 & 0 & 0 & 1 & 0 & 0 \\
\hline 5 & 0 & 0 & 0 & 0 & 0 & 0 & 0 & 0 & 0 & 0 & 0 & 0 \\
\hline Week(s) & \multicolumn{4}{|c|}{7} & \multicolumn{4}{|c|}{8} & \multicolumn{4}{|c|}{9} \\
\hline Score & Control & $\mathrm{DM}$ & $\begin{array}{c}\mathrm{DM}+\mathrm{RSV} \\
\quad(10)\end{array}$ & $\begin{array}{c}\mathrm{DM}+\mathrm{RSV} \\
(30)\end{array}$ & Control & $\mathrm{DM}$ & $\begin{array}{c}\mathrm{DM}+\mathrm{RSV} \\
(10)\end{array}$ & $\begin{array}{c}\mathrm{DM}+\mathrm{RSV} \\
(30)\end{array}$ & Control & $\mathrm{DM}$ & $\begin{array}{c}\mathrm{DM}+\mathrm{RSV} \\
(10)\end{array}$ & $\begin{array}{c}\mathrm{DM}+\mathrm{RSV} \\
(30)\end{array}$ \\
\hline 0 & 20 & 0 & 0 & 0 & 20 & 0 & 0 & 0 & 20 & 0 & 0 & 0 \\
\hline 1 & 0 & 0 & 0 & 0 & 0 & 0 & 0 & 0 & 0 & 0 & 0 & 0 \\
\hline 2 & 0 & 0 & 1 & 4 & 0 & 0 & 0 & 3 & 0 & 0 & 0 & 1 \\
\hline 3 & 0 & 25 & 11 & 16 & 0 & 14 & 9 & 15 & 0 & 4 & 5 & 17 \\
\hline 4 & 0 & 4 & 0 & 0 & 0 & 13 & 3 & 2 & 0 & 14 & 5 & 1 \\
\hline 5 & 0 & 1 & 0 & 0 & 0 & 3 & 0 & 0 & 0 & 12 & 2 & 1 \\
\hline
\end{tabular}

The data represent the number of lenses. Each lens was monitored once a week and scored according to an established scoring scale. Score 0, clear lens (no cataract); score 1, peripheral vesicles and opacities; score 2, central opacities; score 3, diffuse central opacities; score 4, mature cataract; and score 5, hypermature cataract. Control, control rats; $\mathrm{DM}$, diabetic rats; DM+RSV (10), diabetic rats treated with $10 \mathrm{mg} / \mathrm{kg} / \mathrm{d}$ of resveratrol; $\mathrm{DM}+\mathrm{RSV}(30)$, diabetic rats treated with $30 \mathrm{mg} / \mathrm{kg} / \mathrm{d}$ of resveratrol. 
A

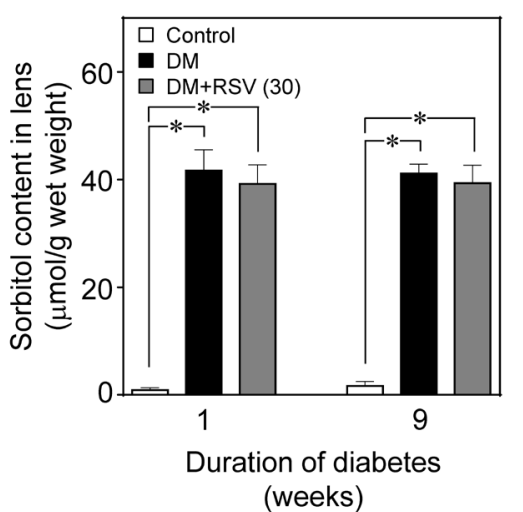

B

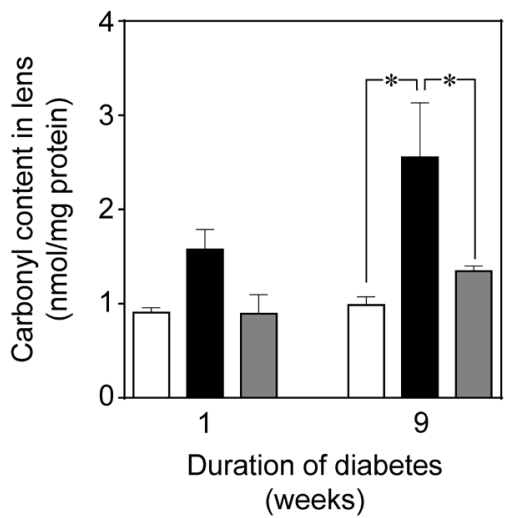

Fig. 4. Changes in Contents of Sorbitol and Protein Carbonyls in the Lens in Control Rats (Control), Diabetic Rats (DM), Diabetic Rats Treated with $30 \mathrm{mg} / \mathrm{kg} / \mathrm{d}$ of Resveratrol [DM+RSV (30)]

Each column with a vertical bar represents the mean \pm S.E. from $3-5$ animals. $* p<0.05$.

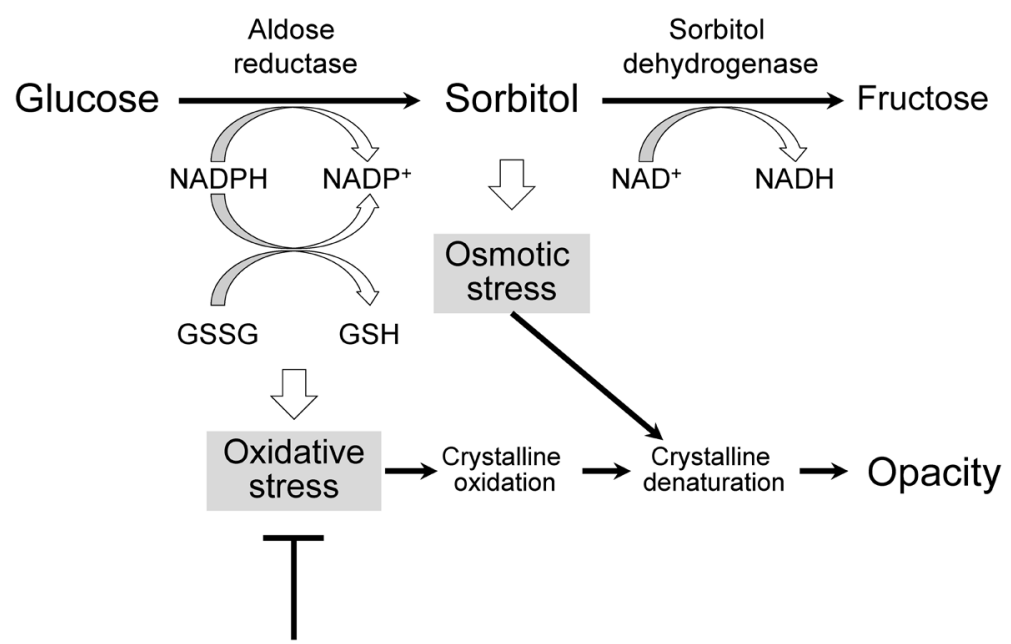

Resveratrol

Fig. 5. A Putative Mechanistic Model for the Anti-cataract Effect of Resveratrol in the Diabetic Rat

Resveratrol attenuates oxidative damage to lens proteins without affecting the activity of polyol pathway.

dependent delay in progression of cataracts was observed in the DM+RSV groups.

Sorbitol and Protein Carbonyl Contents in the Lens In the lenses of diabetic rats, the maximum increase in sorbitol content was observed during the first week after induction of diabetes. This increased level was maintained 9 weeks after induction of diabetes (Fig. 4A). There was no difference in sorbitol contents between the DM and DM+RSV 30 groups.

The content of protein carbonyls in lenses increased in a time-dependent manner in the DM group, whereas it was not significantly enhanced in the DM+RSV 30 group (Fig. 4B).

\section{DISCUSSION}

Potential therapeutic agents that delay the progression of cataract must be carefully evaluated in vivo. The present study clearly demonstrates that resveratrol delays the progression, but not the appearance, of diabetic cataracts in rats. Levels of sorbitol and protein carbonyls were higher in the lenses of diabetic rats than in control rats. Resveratrol suppressed the increasing levels of protein carbonyls, but not those of sorbitol, in diabetic rat lenses. These results suggest that the prevention of oxidative damage to lens proteins partly contributes to the anti-cataract effects of resveratrol (Fig. 5).

Under diabetic conditions, glucose is present at high concentrations in the aqueous humor and can enter the lens by passive, facilitated, and insulin-independent transport mechanisms. ${ }^{26}$ ) Aldose reductase, which is the first enzyme in the polyol pathway, converts glucose to sorbitol, which accumulates because it cannot diffuse passively out of the lens. ${ }^{27)}$ Accumulated sorbitol induces osmotic stress, thereby leading to morphological changes in the lens, such as hydration and swelling. ${ }^{28)}$ In addition, the activated polyol pathway could alter the reduced nicotinamide adenine dinucleotide phosphate (NADPH)/nicotinamide adenine dinucleotide phosphate (NADP) ratio and impair the glutathione peroxidase/ glutathione reductase system thereby decreasing the reduced glutathione/oxidized glutathione ratio that would cause oxidative stress. Higher levels of reactive oxygen species lead to the damage of cellular proteins or lipids. ${ }^{29)}$ In the lens, reactive oxygen species can induce precipitation of soluble proteins, which are responsible for light refraction by oxida- 
tion of sulfhydryl (-SH) groups, as well as the oxidation of polyunsaturated fatty acids. $\left.{ }^{8}\right)$ Previous studies using inhibitors of aldose reductase showed that the polyol pathway plays a critical role in cataract formation during the early stages of diabetes in rats. ${ }^{12,24,30)}$ Indeed, the levels of sorbitol (a measure of polyol pathway activity) and protein carbonyls (a marker of reactive oxygen-mediated protein oxidation) are elevated in diabetic lenses. However, the increase in sorbitol level peaked during the first week after induction of diabetes, whereas protein carbonyl level gradually increased over time. Despite the rapid elevation of sorbitol levels in the first week, cataracts progressed with time over the length of the diabetic period, and mature cataracts were only formed after several weeks. These findings are in line with the generally accepted notion that multiple steps, including oxidative events, are involved in the process of cataract formation.

Resveratrol slowed the formation of cataracts without decreasing the elevated levels of sorbitol in the lens, while it prevented the elevation of the content of protein carbonyls. Thus, under our experimental conditions, resveratrol had no significant effect on the activated polyol pathway. In addition to activation of the polyol pathway, hyperglycemia can generate reactive oxygen species through multiple mechanisms, such as mitochondrial superoxide overproduction, alteration of protein kinase $\mathrm{C}$ activity, and via an increase in advanced glycation end-products. ${ }^{31)}$ Resveratrol can scavenge reactive oxygen species and enhance the expression of various antioxidant enzymes. ${ }^{32,33)}$ The detailed mechanisms are unclear, but the anti-cataract effect of resveratrol seems to be partially attributable to the attenuation of oxidative damage to lens proteins. Further studies are needed to elucidate the precise mechanisms.

Decreased body weight gain, increased water intake, and elevated plasma glucose levels are common symptoms in streptozotocin-induced diabetic rats. The diabetic rats in our study also develop bradycardia, but not hypertension. These symptoms were not improved by resveratrol. Previous studies have demonstrated that resveratrol exhibits a blood glucoselowering effect in streptozotocin-induced diabetic rats. ${ }^{21,34-36)}$ The difference in the effect of resveratrol on blood glucose levels may be attributed to the differences in the degree of hyperglycemia. In this study, severe hyperglycemia was induced by the combination of streptozotocin treatment and D-glucose feeding in order to minimize variability and to hasten the development of diabetic cataracts. In contrast, streptozotocintreated rats were not administered additional D-glucose in previous studies. However, the fact that resveratrol did not prevent the hyperglycemia supports the theory that the inhibitory effects of resveratrol on cataracts cannot be explained by amelioration of hyperglycemia.

A wide range of resveratrol doses $(10-3000 \mathrm{mg} / \mathrm{d})$ has been tested for efficacy against metabolic disorders in clinical studies. ${ }^{37)}$ For a human who weighs $60 \mathrm{~kg}$, that range of resveratrol doses is $0.17-50 \mathrm{mg} / \mathrm{kg} / \mathrm{d}$. Therefore, the effective dose $(30 \mathrm{mg} / \mathrm{kg} / \mathrm{d})$ of resveratrol in this study does not exceed the dose range for clinical use.

In conclusion, we found that resveratrol has the potential to prevent the progression of diabetic cataracts in rats. This beneficial effect of resveratrol is partially attributable to the anti-oxidative effect in diabetic lenses.
Conflict of Interest The authors declare no conflict of interest.

Supplementary Materials The online version of this article contains supplementary materials.

\section{REFERENCES}

1) Jarrett RJ, Keen H. Hyperglycaemia and diabetes mellitus. Lancet, 308, 1009-1012 (1976).

2) Swamy-Mruthinti S, Shaw SM, Zhao HR, Green K, Abraham EC. Evidence of a glycemic threshold for the development of cataracts in diabetic rats. Curr. Eye Res., 18, 423-429 (1999).

3) Wormstone IM. Posterior capsule opacification: A cell biological perspective. Exp. Eye Res., 74, 337-347 (2002).

4) Bockelbrink A, Roll S, Ruether K, Rasch A, Greiner W, Willich SN. Cataract surgery and the development or progression of age-related macular degeneration: a systematic review. Surv. Ophthalmol., 53, 359-367 (2008)

5) Boscia F, Grattagliano I, Vendemiale G, Micelli-Ferrari T, Altomare E. Protein oxidation and lens opacity in humans. Invest. Ophthalmol. Vis. Sci., 41, 2461-2465 (2000).

6) Ozmen B, Ozmen D, Erkin E, Guner I, Habif S, Bayindir O. Lens superoxide dismutase and catalase activities in diabetic cataract. Clin. Biochem., 35, 69-72 (2002).

7) Kyselová Z, Garcia SJ, Gajdosíková A, Gajdosík A, Stefek M. Temporal relationship between lens protein oxidation and cataract development in streptozotocin-induced diabetic rats. Physiol. Res., 54, 49-56 (2005).

8) Thiagarajan R, Manikandan R. Antioxidants and cataract. Free Radic. Res., 47, 337-345 (2013).

9) Kinoshita JH, Kador PF, Catiles M. Aldose reductase in diabetic cataracts. JAMA, 246, 257-261 (1981).

10) Lee AY, Chung SS. Contributions of polyol pathway to oxidative stress in diabetic cataract. FASEB J., 13, 23-30 (1999).

11) Kubo E, Miyoshi N, Fukuda M, Akagi Y. Cataract formation through the polyol pathway is associated with free radical production. Exp. Eye Res., 68, 457-464 (1999).

12) Kawakubo K, Mori A, Sakamoto K, Nakahara T, Ishii K. GP-1447, an inhibitor of aldose reductase, prevents the progression of diabetic cataract in rats. Biol. Pharm. Bull., 35, 866-872 (2012).

13) Lyons TJ, Silvestri G, Dunn JA, Dyer DG, Baynes JW. Role of glycation in modification of lens crystallins in diabetic and nondiabetic senile cataracts. Diabetes, 40, 1010-1015 (1991).

14) Duhaiman AS. Glycation of human lens proteins from diabetic and (nondiabetic) senile cataract patients. Glycoconj. J., 12, 618-621 (1995).

15) Ihm SH, Yoo HJ, Park SW, Ihm J. Effect of aminoguanidine on lipid peroxidation in streptozotocin-induced diabetic rats. Metabolism, 48, 1141-1145 (1999).

16) Baur JA, Sinclair DA. Therapeutic potential of resveratrol: the in vivo evidence. Nat. Rev. Drug Discov., 5, 493-506 (2006).

17) Wu JM, Hsieh TC. Resveratrol: a cardioprotective substance. Ann. N. Y. Acad. Sci., 1215, 16-21 (2011).

18) Richard T, Pawlus AD, Iglésias ML, Pedrot E, Waffo-Teguo P, Mérillon JM, Monti JP. Neuroprotective properties of resveratrol and derivatives. Ann. N. Y. Acad. Sci., 1215, 103-108 (2011).

19) Wood JG, Rogina B, Lavu S, Howitz K, Helfand SL, Tatar M, Sinclair D. Sirtuin activators mimic caloric restriction and delay ageing in metazoans. Nature, 430, 686-689 (2004).

20) Jang M, Cai L, Udeani GO, Slowing KV, Thomas CF, Beecher CW, Fong HH, Farnsworth NR, Kinghorn AD, Mehta RG, Moon RC, Pezzuto JM. Cancer chemopreventive activity of resveratrol, a natural product derived from grapes. Science, 275, 218-220 (1997).

21) Ciddi V, Dodda D. Therapeutic potential of resveratrol in diabetic complications: in vitro and in vivo studies. Pharmacol. Rep., 66 , 
799-803 (2014).

22) Shigematsu $S$, Ishida $S$, Hara $M$, Takahashi $N$, Yoshimatsu H, Sakata T, Korthuis RJ. Resveratrol, a red wine constituent polyphenol, prevents superoxide-dependent inflammatory responses induced by ischemia/reperfusion, platelet-activating factor, or oxidants. Free Radic. Biol. Med., 34, 810-817 (2003).

23) Kametaka S, Kasahara T, Ueo M, Takenaka M, Saito M, Sakamoto $\mathrm{K}$, Nakahara $\mathrm{T}$, Ishii $\mathrm{K}$. A novel high resolution in vivo digital imaging system for the evaluation of experimental cataract in diabetic rats. J. Pharmacol. Sci., 106, 144-151 (2008).

24) Ashizawa N, Yoshida M, Sugiyama Y, Akaike N, Ohbayashi S, Aotsuka T, Abe N, Fukushima K, Matsuura A. Effects of a novel potent aldose reductase inhibitor, GP-1447, on aldose reductase activity in vitro and on diabetic neuropathy and cataract formation in rats. Jpn. J. Pharmacol., 73, 133-144 (1997).

25) Mori A, Saigo O, Sakamoto K, Nakahara T, Ishii K. Hyperglycemia impairs acetylcholine-induced vasodilation of retinal arterioles through polyol pathway-independent mechanisms in rats. J. Pharmacol. Sci., 112, 336-342 (2010).

26) Patterson JW. A review of glucose transport in the lens. Invest. Ophthalmol., 4, 667-679 (1965).

27) Srivastava SK, Ramana KV, Bhatnagar A. Role of aldose reductase and oxidative damage in diabetes and the consequent potential for therapeutic options. Endocr. Rev., 26, 380-392 (2005).

28) Burg MB, Kador PF. Sorbitol, osmoregulation, and the complications of diabetes. J. Clin. Invest., 81, 635-640 (1988).

29) Maritim AC, Sanders RA, Watkins JB 3rd. Diabetes, oxidative stress, and antioxidants: a review. J. Biochem. Mol. Toxicol., 17, 24-38 (2003)

30) Ao S, Shingu Y, Kikuchi C, Takano Y, Nomura K, Fujiwara T, Ohkubo Y, Notsu Y, Yamaguchi I. Characterization of a novel aldose reductase inhibitor, FR74366, and its effects on diabetic cataract and neuropathy in the rat. Metabolism, 40, 77-87 (1991).

31) Giacco F, Brownlee M. Oxidative stress and diabetic complications. Circ. Res., 107, 1058-1070 (2010).

32) Oyenihi OR, Oyenihi AB, Adeyanju AA, Oguntibeju OO. Antidiabetic effects of resveratrol: The way forward in Its clinical utility. $J$. Diabetes Res., 2016, 9737483 (2016).

33) Truong VL, Jun M, Jeong WS. Role of resveratrol in regulation of cellular defense systems against oxidative stress. Biofactors, 44, 36-49 (2018).

34) Su HC, Hung LM, Chen JK. Resveratrol, a red wine antioxidant, possesses an insulin-like effect in streptozotocin-induced diabetic rats. Am. J. Physiol. Endocrinol. Metab., 290, E1339-E1346 (2006).

35) Silan C. The effects of chronic resveratrol treatment on vascular responsiveness of streptozotocin-induced diabetic rats. Biol. Pharm. Bull., 31, 897-902 (2008).

36) Chang CC, Chang CY, Wu YT, Huang JP, Yen TH, Hung LM. Resveratrol retards progression of diabetic nephropathy through modulations of oxidative stress, proinflammatory cytokines, and AMP-activated protein kinase. J. Biomed. Sci., 18, 47 (2011).

37) Szkudelski T, Szkudelska K. Resveratrol and diabetes: from animal to human studies. Biochim. Biophys. Acta, 1852, 1145-1154 (2015). 